\title{
Reliability of heart rate variability in futsal players
}

http://dx.doi.org/10.11606/1807-5509202000040673

\author{
Ana Carolina Paludo* \\ Tiago Peçanha* \\ Felipe N. Rabelo** \\ Rhenan Bartels*** \\ Rafael Y. Fecchio* \\ Antonio Carlos Simões* \\ Fábio Y. Nakamura**********
}

\begin{abstract}
The main aim the present study was evaluated the reliability of the heart rate variability (HRV) indices in futsal players. Additionally the study verified the reliability of different approaches for $5 \mathrm{~min}$ interval selection of recording. Eighteen under-20 futsal players underwent 15 min of pre-training RR interval recordings in two different day. Time and frequency domain and Poincaré Plot indices were tested. The indices were calculated using: 1) final 5 min of recording; 2) 5 min of lower variance of recording, by a mathematical algorithm; 3) 5 min segment of lower variance, by an experienced operator. The HRV indices presented a wide range reliability [e.g. RRmean (ICC $=0.96, \mathrm{SEM}=3.4 \mathrm{~ms}, \mathrm{CV}=2.6 \%)$, InRMSSD (ICC $=0.88, \mathrm{SEM}=5.9 \mathrm{~ms}$, $\mathrm{CV}=4.3 \%), \operatorname{InHF}(I C C=0.89$, SEM=7.5ms, CV=5.9\%), LFnu (ICC=0.84, SEM=13ms, CV=9.4\%), LF $(I C C=0.47$, $\mathrm{SEM}=65.2 \mathrm{~ms}, \mathrm{CV}=38.5 \%)$ and $\mathrm{LF} / \mathrm{HF}(\mathrm{ICC}=0.63, \mathrm{SEM}=83.7 \mathrm{~ms}, \mathrm{CV}=54.5 \%)]$. The final $5 \mathrm{~min}$ of recording was the most reliable. The results suggest that most of HRV indices presented acceptable reliability, however the RRmean, InRMSSD, InHF and LFnu were the most reliable.
\end{abstract}

KEYWORDS: Autonomic nervous system; Athletes; Reproducibility; Test-retest.

\section{Introduction}

Heart rate variability (HRV) is a non-invasive marker reflecting the activity of sympathetic and vagal components of autonomic nervous systems on the sinus node $^{1,2}$. Analyses of HRV mostly consist of quantifying variations in time series of successive heart beats (i.e RR intervals), using statistical or spectral methods. In general, at rest, $\mathrm{HRV}$ is high due to the predominance of vagal activity on the heart ${ }^{3}$. Under physical exercise or emotional stress, the HRV tends to decrease in response to an increase in sympathetic activity ${ }^{3,4}$.

The HRV analysis has been consistently employed in clinical settings, due its capacity to predict the development of cardiovascular disease and mortality5. More recently, HRV analysis has also been used to track seasonal changes in physical fitness and performance ${ }^{6-9}$, to quantify the effects of training load on cardiovascular homeostasis ${ }^{10,11}$ and to predict unfavourable psychological stats such as anxiety and stress pre-competition ${ }^{12,13}$. Moreover, $\mathrm{HRV}$ indices can be used to prevent excessive fatigue and overtraining in several sports modalities ${ }^{14,15}$.

Despite this broad application of HRV analysis in the sports field, the HRV reliability in athletes under a typical training condition is poorly known. This knowledge is essential, considering that the level of HRV reliability in sport may determine its capacity to generate accurate information for coaches and sports physiologists ${ }^{16,17}$. In addition, the widespread use of HRV in sport context, the identification of the most reliable indices (e.g. timedomain, frequency-domain and non-linear), the standardization of methodological aspects of HRV calculation, and the proper choice of the RR interval segment for HRV analysis are matters of concern ${ }^{18}$.
*School of Physical Education and Sport University of São Paulo, São Paulo, SP, Brazil.

** Atlético Paranaense Club, Curitiba, PR, Brazil.

** * B i o m e di c a Engineering Program, Federal University of Rio de Janeiro, Rio de Janeiro, RJ, Brazil. ****College of Healthcare Science, James Cook University, Queensland, Australia. $\star \star \star \star \star *$ Nucleus of High Performance in Sport, São Paulo, SP, Brazil. 
According to the Task Force for HRV analysis short-term resting measurements of HRV should be conducted using stationary 5 min segments ${ }^{19}$. However, there is scarce information regarding to the best methods for selection of the proper segment for analysis; and the literature has used different approaches, such as the last 5 min segment of the whole recording ${ }^{20,21}$, the 5 min segment of lower variance as defined by mathematical algorithms $\mathrm{s}^{22,23}$ and the 5 min segment of lower variance as defined by experienced evaluators ${ }^{24,25}$. The reliability of HRV might vary between these different methods,

\section{Methods}

\section{Experimental design}

The study was performed at the beginning of preparatory training cycle. All participants were evaluated in two different days (test and retest) with 24 hours apart, in the team's own training centre. Beat-to-beat heart rate was recorded during 15 min period, between 9:00 and 9:30 am, using a portable heart rate monitor (Polar Team ${ }^{2}$ Pro, Kempele, Finland), well-adjusted with an electrode transmitter belt firmly held around thorax. The players remained seated in rest inside the locker room $\left(21-22^{\circ} \mathrm{C}\right)$ during data collection. The participants were instructed to remain quiet, breath spontaneously and keep their eyes open. To prevent any confounding variables, the participants were also instructed to avoid any exercise in the morning of evaluation and to follow their normal sleep and dietary habits before the evaluations. In the day between test and retest, athletes performed a moderate-intensity training session (session rating of perceived exertion between 3-4 in the Borg CR-10 scale $\left.{ }^{28}\right)$. Data collection was conducted at the same time period to minimise the influence of circadian variation ${ }^{29}$ and under training conditions, to improve the ecological validity.

\section{Participants}

Eighteen U-20 male futsal players were recruited for this study (age: $18 \pm 2$ years; height: $1.77 \pm$ $0.5 \mathrm{~m}$; body mass: $71.6 \pm 7 \mathrm{~kg}$ ). Participants were professional players from the same team with average $10.4 \pm 1.8$ years of experience in futsal. The participants were not taking prescribed medications but the reliability of different methods for interval selection has not been tested yet.

Therefore, the aim of this study was to examine the reliability of time and frequency domains, and non-linear indices of HRV recorded in a cohort of professional futsal players in real training settings. Additionally, this study aimed to verify the reliability of different approaches for $5 \mathrm{~min}$ interval selection. Based on previous studies, we hypothesized that the time domain indices would be more reliable ${ }^{26,27}$, and that the mathematical selection of the most stationary segment would improve the HRV reliability.

or any special dietary supplement and did not report any cardiovascular disease. The procedures were conducted with approval of the Ethics Committee of the local University ( $\mathrm{n}^{\circ} 544.410 / 2014$ ), and the informed consent was obtained from each participant, prior to study commencement.

\section{Interval selection procedures}

HRV indices were assessed in a single $5 \mathrm{~min}$ segment extracted from the original $15 \mathrm{~min}$ of recordings. To address the possible influence of the segment selection on HRV reliability, we tested three different methods: 1) the final 5 min of recordings; 2) the 5 min showing lower variance in the signal determined by a Matlab algorithm (The Math Works, Massachusetts, USA); 3) the 5 min showing lower variance in the signal as visually examined by an experienced operator.

\section{Determination of HRV indices}

The heart rate monitor data was downloaded on computer using Polar software (Polar ${ }^{\circ}$ Pro Trainer, Kempele, Finland) and exported as a text file to Kubios 2.0 (Biosignal Analysis and Medical Imaging Group, Finland) for HRV analysis. The analysis was performed according to the Task Force of The European Society of Cardiology and The North American Society of Pacing and Electrophysiology ${ }^{19}$. Time and frequency domains and Poincaré plot non-linear indices were calculated. Time domain indices included mean R-R internal (RRmean), the standard deviation of all $R R$ interval (SDNN), the absolute square root of the mean of the sum of the squares of differences between 
adjacent RR interval (RMSSD) and natural logarithm transformed RMSSD (lnRMSSD), and the percentage of beats that varied more than $50 \mathrm{~ms}$ from the previous beat ( $\mathrm{pNN} 50)$. For the frequency domain analysis, firstly a Smooth Prior function was applied in the entire signal in order to remove the slow trends components. Afterwards, the signal was re-sampled in $4 \mathrm{~Hz}$ using cubic splines and the Fast Fourier Transform (FFT) method was used to perform the spectral decomposition of the signal. The bands of low (LF: $0.04-0.15 \mathrm{~Hz}$ ) and high (HF: $0.15-0.4 \mathrm{~Hz}$ ) frequencies, either in absolute, natural logarithm-transformed (ln) or normalized (nu) units were calculated. The ratio between $\mathrm{LF}$ and $\mathrm{HF}$ was also reported. Finally, regarding the non-linear analysis, the SD1 (instantaneous beat-to-beat variability) and SD2 (long-term beat-to-beat variability) indices were calculated from the Poincaré plot.

\section{Statistical analysis}

Normal Gaussian distribution of the data was confirmed by the Shapiro-Wilk test and the descriptive data was exposed in mean and standard

\section{Results}

TABLE 1 summarises the means values (test and retest) and the reliability parameters of data obtained using the final $5 \mathrm{~min}$ of recordings. There were no significant differences between test and retest mean values $(P>0.05)$. Relative reliability examined by ICC ranged from near perfect (RRmean: 0.96; pNN50: 0.94) to moderate (LF: 0.47). Absolute reliability examined by $\mathrm{CV}$ ranged from $2.6 \%$ (RRmean) to $54.5 \%$ (LF/HF). SEMs vary between these measures as described in TABLE 1.

TABLE 2 shows the mean values (test and retest) and the reliability of the $5 \mathrm{~min}$ of lower variance of the signal selected by algorithm. HRV did not differ between test and retest $(P>0.05)$. Relative reliability was near perfect for RRmean $(\mathrm{ICC}=0.93$ ) and small to moderate for LF (ICC=0.48), LF/ FH $(\mathrm{ICC}=0.30)$ and SD2 (ICC=-0.15). Absolute reliability examined by $\mathrm{CV}$ ranged from $3.7 \%$ deviation. The reliability of the HRV indices was assessed by the following parameters: 1) the presence of systematic bias; 2) relative reliability; and 3) absolute reliability. The presence of systematic bias was evaluated by the comparison of test and retest mean values through the paired Student's t-test. Relative reliability was examined by intraclass correlation coefficient (ICC) and was classified according to Hopkins et al. ${ }^{30}$ following the thresholds: 0 to 0.30 small, 0.31 . to 0.49 moderate, 0.50 to 0.69 large, 0.70 to 89 very large, and 0.90 to 1 near perfect. Absolute reliability was assessed by the standard error of measurement (SEM), using the formula: $\mathrm{SDD} / \sqrt{ } 2$, where $\mathrm{SDD}$ = standard deviation of the differences between test and retest data. Moreover, to allow comparisons between the different HRV indices, the absolute reliability was also expressed by a coefficient of variation $(\mathrm{CV})$, calculated by a quotient between SEM and the mean value between test and retest data. All statistical analyses were conducted using SPSS 19 and the statistical significance was set at $P \leq 0.05$ level.
(RRmean) to $75.5 \%$ (LF/HF). SEMs vary between these measures as described in TABLE 2.

TABLE 3 presents the mean values (test and retest) and information regarding the reliability analysis of the $5 \mathrm{~min}$ of lower variance defined by an experienced operator. Only SD2 was significantly different between test and retest $(\mathrm{P}<0.05)$. Relative reliability ranged from near perfect for RRmean (ICC $=0.93$ ) to moderate for LF ( ICC $=0.38$ ). CVs ranged between 3.8\% (RRmean) and 50.5\% $(\mathrm{HF})$ and SEMs vary between these measures as described in TABLE 3.

TABLE 4 shows the comparison of the most reliable indices (RRmean, lnRMSSD, lnHF and LFnu) amongst the three different approaches of interval selection. The final $5 \mathrm{~min}$ of recordings showed slightly superior values of ICC, SEM and $\mathrm{CV}$ within the most reliable indices. 
Paludo AC, et al.

TABLE 1 - Reliability of the interval selection of final 5-min of signal recordings procedure.

\begin{tabular}{|c|c|c|c|c|c|c|}
\hline & HRV indice & $\begin{array}{c}\text { Measure } \\
\text { 1(mean } \pm \text { SD) }\end{array}$ & $\begin{array}{c}\text { Measure } 2 \\
(\text { mean } \pm S D)\end{array}$ & ICC & SEM & CV (\%) \\
\hline $\begin{array}{l}\text { SD = standard } \\
\text { deviation; }\end{array}$ & Time Domain & & & & & \\
\hline $\begin{array}{l}\text { ICC = intraclass } \\
\text { correlation coefficient; }\end{array}$ & RRmean & $807.2 \pm 93.2$ & $818.8 \pm 107.9$ & 0.96 & 3.4 & 2.6 \\
\hline $\begin{array}{l}\text { SEM = standard error } \\
\text { of measurement; }\end{array}$ & SDNN & $51.1 \pm 20.2$ & $48.8 \pm 13.7$ & 0.73 & 22.3 & 14.5 \\
\hline $\begin{array}{l}C V=\text { coefficient of } \\
\text { variation. }\end{array}$ & RMSSD & $41.5 \pm 19.6$ & $40.6 \pm 19.2$ & 0.88 & 21.7 & 16.2 \\
\hline & $\operatorname{lnRMSSD}$ & $3.6 \pm 0.5$ & $3.6 \pm 0.4$ & 0.88 & 6.0 & 4.3 \\
\hline & pNN50 \% & $18.5 \pm 14.6$ & $18 \pm 15.5$ & 0.94 & 28.2 & 21.5 \\
\hline & Frequency Don & & & & & \\
\hline & $\mathrm{LF}$ & $1877.9 \pm 1744.9$ & $1604 \pm 851.2$ & 0.47 & 65.2 & 38.5 \\
\hline & $\operatorname{lnLF}$ & $7.2 \pm 0.8$ & $7.2 \pm 0.6$ & 0.65 & 6.9 & 4.6 \\
\hline & $\mathrm{LF}_{\mathrm{nu}}$ & $71.4 \pm 17.6$ & $71.9 \pm 16.9$ & 0.84 & 13.0 & 9.4 \\
\hline & $\mathrm{HF}$ & $743.6 \pm 639.9$ & $745.6 \pm 850.5$ & 0.89 & 45.3 & 38.3 \\
\hline & $\ln \mathrm{HF}$ & $6.2 \pm 1.0$ & $6.1 \pm 1.1$ & 0.89 & 7.5 & 5.9 \\
\hline & $\mathrm{HF}_{\mathrm{nu}}$ & $28.6 \pm 17.6$ & $28.1 \pm 16.9$ & 0.84 & 32.8 & 24 \\
\hline & LF/HF & $4.6 \pm 5.3$ & $4.3 \pm 3.2$ & 0.63 & 83.7 & 54.5 \\
\hline & $\operatorname{lnLF} / \mathrm{HF}$ & $1.1 \pm 1.0$ & $1.2 \pm 0.9$ & 0.71 & 54.3 & 39.9 \\
\hline & Poincaré Plot & & & & & \\
\hline & SD1 & $29.8 \pm 14$ & $29.1 \pm 13.6$ & 0.88 & 21.6 & 16.2 \\
\hline & SD2 & $102.2 \pm 44.3$ & $94.4 \pm 27.5$ & 0.74 & 24.1 & 14.9 \\
\hline
\end{tabular}

676 • Rev Bras Educ Fís Esporte, (São Paulo) 2020 Out-Dez;34(4):673-83 
TABLE 2 - Reliability of the interval selection of 5-min showing less variance by Matlab software routine procedure.

\begin{tabular}{|c|c|c|c|c|c|}
\hline HRV indice & $\begin{array}{c}\text { Measure } \\
\text { 1(mean } \pm \text { SD })\end{array}$ & $\begin{array}{c}\text { Measure } 2 \\
(\text { mean } \pm \text { SD) }\end{array}$ & ICC & SEM (\%) & CV (\%) \\
\hline \multicolumn{6}{|l|}{ Time Domain } \\
\hline RRmean & $826.40 \pm 113$ & $817.2 \pm 115.5$ & 0.93 & 4.9 & 3.7 \\
\hline SDNN & $44.9 \pm 18.1$ & $41.2 \pm 10.9$ & 0.83 & 18.6 & 10.7 \\
\hline RMSSD & $38.6 \pm 19.1$ & $34.6 \pm 15.9$ & 0.88 & 22.3 & 16 \\
\hline $\operatorname{lnRMSSD}$ & $3.5 \pm 0.5$ & $3.4 \pm 0.4$ & 0.89 & 6.1 & 4.2 \\
\hline $\mathrm{pNN} 50$ & $17.8 \pm 16.4$ & $13.7 \pm 13.9$ & 0.88 & 44.3 & 34.5 \\
\hline \multicolumn{6}{|c|}{ Frequency Domain } \\
\hline $\mathrm{LF}$ & $1434 \pm 1300.3$ & $1187.2 \pm 506.1$ & 0.48 & 62 & 30.6 \\
\hline $\operatorname{lnLF}$ & $7.0 \pm 0.7$ & $7.0 \pm 0.5$ & 0.66 & 6.1 & 4.3 \\
\hline $\mathrm{LF}_{\mathrm{nu}}$ & $71 \pm 11.6$ & $74.1 \pm 14.9$ & 0.68 & 13.2 & 11.4 \\
\hline $\mathrm{HF}$ & $617.2 \pm 601.7$ & $943.7 \pm 478.8$ & 0.75 & 62.3 & 48.9 \\
\hline $\ln \mathrm{HF}$ & $6.0 \pm 1.0$ & $5.8 \pm 1.0$ & 0.86 & 8.6 & 6.6 \\
\hline $\mathrm{HF}_{\mathrm{nu}}$ & $29 \pm 11.7$ & $25.9 \pm 14.8$ & 0.68 & 34.9 & 32.4 \\
\hline $\mathrm{LF} / \mathrm{HF}$ & $3.1 \pm 1.9$ & $4.9 \pm 4.4$ & 0.30 & 78.4 & 75.5 \\
\hline $\operatorname{lnLF} / \mathrm{HF}$ & $1.0 \pm 0.6$ & $1.2 \pm 0.9$ & 0.63 & 52.5 & 44.4 \\
\hline \multicolumn{6}{|l|}{ Poincaré Plot } \\
\hline SD1 & $27.6 \pm 13.6$ & $24.7 \pm 11.3$ & 0.88 & 22.2 & 15.8 \\
\hline SD2 & $76.5 \pm 30.3$ & $105.7 \pm 132.6$ & 0.15 & 108.1 & 132.5 \\
\hline
\end{tabular}

$\mathrm{SD}=$ standard deviation;

ICC $=$ intraclass correlation coefficient SEM = standard error of measurement; $\mathrm{CV}=$ coefficient of variation. 
Paludo AC, et al.

TABLE 3 - Reliability of the interval selection of 5-min showing less variance of signal visually examined procedure.

$*=P<0.05$ between
measure 1 and
measure 2 ;
SD = standard
deviation;
ICC = intraclass
correlation coefficient;
SEM = standard error
of measurement;
$C V=$ coefficient of
variation.

\begin{tabular}{|c|c|c|c|c|c|}
\hline HRV indice & $\begin{array}{c}\text { Measure } \\
\text { 1(mean } \pm S D)\end{array}$ & $\begin{array}{c}\text { Measure } 2 \\
(\text { mean } \pm S D)\end{array}$ & ICC & SEM & CV (\%) \\
\hline \multicolumn{6}{|l|}{ Time Domain } \\
\hline RRmean & $832.1 \pm 111.4$ & $825.1 \pm 119.8$ & 0.93 & 5 & 3.8 \\
\hline SDNN & $47.8 \pm 18.8$ & $46.4 \pm 13.2$ & 0.77 & 20.9 & 13.5 \\
\hline RMSSD & $41.7 \pm 19.9$ & $39.7 \pm 19.2$ & 0.87 & 23.2 & 17.6 \\
\hline $\operatorname{lnRMSSD}$ & $3.6 \pm 0.5$ & $3.6 \pm 0.5$ & 0.88 & 6.3 & 4.6 \\
\hline pNN50 & $19.5 \pm 16.9$ & $17.8 \pm 15.4$ & 0.91 & 34.5 & 25.5 \\
\hline
\end{tabular}

Frequency Domain

\begin{tabular}{|c|c|c|c|c|c|}
\hline $\mathrm{LF}$ & $1712.4 \pm 1610.3$ & $1267.5 \pm 541.1$ & 0.38 & 70.9 & 33.5 \\
\hline $\operatorname{lnLF}$ & $7.1 \pm 0.7$ & $7.0 \pm 0.5$ & 0.65 & 6.2 & 4.1 \\
\hline $\mathrm{LF}_{\mathrm{nu}}$ & $70.7 \pm 13.8$ & $73.3 \pm 13.6$ & 0.76 & 12.1 & 9.1 \\
\hline $\mathrm{HF}$ & $726.9 \pm 675.4$ & $600.3 \pm 605.8$ & 0.75 & 61.2 & 50.5 \\
\hline $\ln \mathrm{HF}$ & $6.2 \pm 0.9$ & $5.9 \pm 1.0$ & 0.88 & 8.2 & 6.2 \\
\hline $\mathrm{HF}_{\mathrm{nu}}$ & $29.3 \pm 13.8$ & $26.6 \pm 13.6$ & 0.76 & 7.4 & 25 \\
\hline $\mathrm{LF} / \mathrm{HF}$ & $3.3 \pm 2$ & $4.1 \pm 3.1$ & 0.61 & 53.6 & 47.1 \\
\hline $\operatorname{lnLF} / \mathrm{HF}$ & $1.0 \pm 0.7$ & $1.1 \pm 0.8$ & 0.75 & 44.6 & 34.1 \\
\hline \multicolumn{6}{|l|}{ Poincaré Plot } \\
\hline SD1 & $29.8 \pm 14.2$ & $28.4 \pm 13.6$ & 0.86 & 23.1 & 17.5 \\
\hline SD2 & $31.7 \pm 18.2$ & $78.7 \pm 30.9^{*}$ & 0.67 & 23.6 & 15.9 \\
\hline
\end{tabular}

678 • Rev Bras Educ Fís Esporte, (São Paulo) 2020 Out-Dez;34(4):673-83 
TABLE 4 - Reliability of the best HRV indices results by three different interval of selection approaches.

\begin{tabular}{|c|c|c|c|}
\hline & The last $5 \mathrm{~min}$ & $\begin{array}{c}\text { The } 5 \text { min of less variance by } \\
\text { Matlab routine }\end{array}$ & $\begin{array}{c}\text { The } 5 \text { min of less variance } \\
\text { visually }\end{array}$ \\
\hline \multicolumn{4}{|l|}{ ICC } \\
\hline RRmean & 0.96 & 0.93 & 0.93 \\
\hline $\operatorname{lnRMSSD}$ & 0.89 & 0.89 & 0.88 \\
\hline $\operatorname{lnHF}$ & 0.89 & 0.84 & 0.86 \\
\hline $\mathrm{LF}_{\mathrm{nu}}$ & 0.84 & 0.68 & 0.76 \\
\hline \multicolumn{4}{|l|}{ SEM } \\
\hline RRmean & 3.4 & 4.9 & 5 \\
\hline $\operatorname{lnRMSSD}$ & 5.9 & 6.1 & 6.3 \\
\hline $\operatorname{lnHF}$ & 5.9 & 8.6 & 8.2 \\
\hline $\mathrm{LF}_{\mathrm{nu}}$ & 13 & 13.2 & 12.1 \\
\hline \multicolumn{4}{|l|}{$C V(\%)$} \\
\hline RRmean & 2.6 & 3.7 & 3.8 \\
\hline $\operatorname{lnRMSSD}$ & 4.2 & 4.2 & 4.6 \\
\hline $\ln \mathrm{HF}$ & 7.5 & 6.9 & 6.6 \\
\hline $\mathrm{LF}_{\mathrm{nu}}$ & 9.4 & 11.4 & 9.1 \\
\hline
\end{tabular}

ICC = intraclass correlation coefficient; SEM = standard error of measurement; $\mathrm{CV}=$ coefficient of variation.

\section{Discussion}

The current results demonstrated that in a typical sport setting, the degree of reliability varies substantially amongst the different HRV indices. The most reliable indices in futsal players were: RRmean, lnRMSSD, lnHF and $\mathrm{LF}_{\text {nu }}$; and the less reliable were: LF and LF/HF. In addition, the reliability of the most reliable HRV indices was influenced by internal selection procedure, with better results for the approach that takes the final 5 min of recordings. To date, this is the first study that determined the reliability of time and frequency domain, and non-linear HRV indices in team-sport athletes under a typical sport training condition, thus presenting a high ecological validity.

Relative and absolute reliability of HRV indices in the time and frequency domains under rest condition have been previously investigated in different populations ${ }^{26,31,32}$. In accordance with the studies aforementioned, the present study have also reported better reliability for time domain indices $(\mathrm{ICC}=0.73-0.96 ; \mathrm{CV}=2.6-21.6 \%)$ than for frequency domain indices (ICC $=0.47-$ 0.89 ; $\mathrm{CV}=4.6-54.5 \%)$. Indeed, time-domain indices seems to be less influenced than frequencydomain indices to internal or external influences, such as the presence of ectopic beats in RR time series, variations in breathing pattern or changes in psychological states ${ }^{19,33}$. This great robustness might help to explain the general higher reliability of the time domain in comparison with frequency domain indices. However, some frequency domain indices also presented acceptable reliability in the present study [e.g, $\ln \mathrm{HF}(\mathrm{ICC}=0.89)$ and $\mathrm{HF}_{\text {nu }}(\mathrm{ICC}=0.84)$ indices in the final 5-min of recordings approach]. In this respect, the frequency-domain indices showing the highest reliability in the present study were those transformed by natural logarithm or normalized units. These transformations reduce 
the variability of such indices, either by adjusting the skewness of power values distributions ${ }^{34}$ or by normalizing to the total power of the signal. These mathematical transformations should then, be encouraged for improving the reliability of frequency-domain.

It is worth to highlight that all of the studies of HRV reliability mentioned were conducted with non-athletes participants, under laboratory controlled conditions. These characteristics limit generalizations on the reliability of the HRV indices in athletes under a typical sport condition. In this sense, the degree of reliability is population specific $^{35}$ and this is certainly true for athletes, whereas they deal with psychophysiological stresses in a daily basis, which acutely change cardiovascular autonomic function ${ }^{8,9,12}$. In line with these assumptions, the present study shows that the heart rate index (RRmean) was more reliable than LF (for both transformed and non-transformed data), while Pitzalis et al. ${ }^{36}$ demonstrated opposite results in healthy participants. The divergent results suggested that the reliability of some HRV parameters might be different between athletes and non-athletes.

To our knowledge, only one study has assessed HRV reliability in professional athletes. Accordingly, NAKAMURA et al. ${ }^{37}$ has recently observed a good intra- and inter-day reliability of InRMSSD in female rugby players $(\mathrm{ICC}=0.96$ and 0.90 ; $\mathrm{CV}$ $=3.9$ and $7.6 \%$, respectively), which is in close agreement to the results of the present study for the same index $(\mathrm{ICC} \approx 0.90$ and $\mathrm{CV} \approx 4 \%$ ). Nonetheless, the authors have not evaluated other indices, which preclude further comparison with our study. Thus, more studies with athletes are necessary in order to confirm the current findings and to extend the knowledge on HRV reliability in sport science.

The second goal of the present study was to verify if different approaches for $5 \mathrm{~min}$ interval selection would impact the HRV variability in the current experimental setup. The Task Force for HRV analysis ${ }^{19}$ recommends that short-term resting measurements should be conducted using stationary 5 min segments. Based on that, we have tested the reliability of HRV indices using three commonly used approaches for segment selection. In this regard, the three approaches presented similar reliability for the most reliable HRV indices, with the 5 min of recordings performed slightly better than the other methods. In view of the small differences when evaluating athletes are meaningful ${ }^{38}$, even a slight improvement in the HRV reliability may be relevant. To data, we are unaware of any other study that have tested the effect of different procedures of interval selection on HRV reliability, thus, it is not possible a deep discussion of the current findings under the light of the literature evidence. However, it is noticeable that the final $5 \mathrm{~min}$ of recordings procedure has been used in previous studies for evaluation of HRV in pre-training conditions ${ }^{9,12}$, and the results of the present study gives support for the use of such a practical approach.

The current findings have important applications for the use of HRV indices in the sports field. Relative reliability defines the capacity of measurements in distinguish the participants from each other ${ }^{16,35}$. In turn, absolute reliability results provide parameters for establish the minimal change that can be attributed to a real effect of intervention and not a random variation when evaluating individual responses ${ }^{16,35}$. Some authors suggest that threshold of two times the SEM is reasonable to decide if a real chance occurred ${ }^{17}$. Thus, the current findings imply that the time domain indices and the final 5 min of recordings may be preferred in the sports field when the goals are to distinguish or rank athletes between them, which would allow the identification of the athletes with worse physiological and physical status. Moreover, these indices could be more sensitive to detect real changes due to seasonal or training effects, which would allow the individual monitoring of these athletes in each specific micro-cycle.

One limitation of the present study was the evaluation of a specific population (futsal players); for this reason, it is not possible to extend the present results to other sports modalities. In addition, caution is necessary when extrapolating the present findings to females. We recommended for the future studies the inclusion of large samples, including women and different sports modalities. The absence of respiratory rate control could also be considered a limitation, since previous research showed that reliability of HRV measures increase when respiratory ${ }^{39}$. However, the aim of this study was to explore the HRV in a real futsal training condition, and the employment of respiratory rate control could reduce the ecological validity of the study.

Lastly, the training session between test and retest days should be considered a limiting factor. Even though considered a moderate-intensity 
session, the HRV may have been influenced in the second day.

The majority of HRV indices in time and frequency domain presented acceptable reliability, however, the most reliable indices were: RRmean $\ln \mathrm{RMSSD}, \ln \mathrm{HF}$ and $\mathrm{LF}_{\mathrm{nu}}$; and the least reliable indices were LF/HF and LF. Furthermore, the procedure of interval selection that showed the best values of reliability was the final 5 min of recordings. This variation in HRV reliability according to the index and the procedure of interval selection used should be considered in the futsal sport setting.

\section{Acknowledgements}

The authors wish to acknowledge the committed participation of all futsal players, staff and coaches involved in this study. This work was support by the CAPES foundation, a Brazilian Agency for Support and Evaluation of Graduate Education.

\section{Resumo}

Reprodutibilidade da variabilidade da frequência cardíaca em jogadores de futsal.

0 presente estudo avaliou a reprodutibilidade dos índices da variabilidade da frequência cardíaca (VFC) em jogadores de futsal. Adicionalmente, o presente estudo verificou a reprodutibilidade de diferentes abordagens para seleção dos intervalos de registro. Dezoito jogadores de futsal Sub-20 foram avaliados durante 15-min de registro dos intervalos RR, pré-treino em dois dias diferentes. Os índices de domínio do tempo e frequência e Poincaré Plot foram testados. Os índices foram calculados usando: 1) registro dos últimos $5 \mathrm{~min}$; 2) 5 min de registro com menor variação, por um algoritmo matemático; 3) 5 min do seguimento de menor variação, por um avaliador experiente. Os índices de VFC apresentaram alta amplitude de reprodutibilidade [ex: RRmen (ICC=0.96, SEM=3.4ms, CV=2.6\%), InRMSSD (ICC $=0.88, S E M=5.9 m s, C V=4.3 \%), \operatorname{InHF}(I C C=0.89$, $\mathrm{SEM}=7.5 \mathrm{~ms}, \mathrm{CV}=5.9 \%), \mathrm{LF}_{\text {nu }}(\mathrm{ICC}=0.84, \mathrm{SEM}=13 \mathrm{~ms}, \mathrm{CV}=9.4 \%), \mathrm{LF}(\mathrm{ICC}=0.47, \mathrm{SEM}=65.2 \mathrm{~ms}, \mathrm{CV}=38.5 \%)$ and $\mathrm{LF} / \mathrm{HF}(\mathrm{ICC}=0.63, \mathrm{SEM}=83.7 \mathrm{~ms}, \mathrm{CV}=54.5 \%)]$. 0 registro dos $5 \mathrm{~min}$ finais foram os mais reprodutíveis. Os resultados sugerem que a maioria dos índices de VFC apresentaram reprodutibilidade aceitável, contudo o RRmean, InRMSSD, InHF e LF ${ }_{\text {nu }}$ foram os mais reprodutiveis.

Palavras-Chave: Sistema nervoso autonômico; Atletas, Reprodutibilidade; Teste-reteste.

\section{References}

1. Sztajzel J. Heart rate variability: a noninvasive electrocardiographic method to measure the autonomic nervous system. Swiss Med Wkly. 2004;134:514-522.

2. Van Ravenswaaij-Arts CM, Kollee LA, Hopman JC, et al. Heart rate variability. Anna Intern Med. 1993;118:436447.

3. Montano N, Ruscone TG, Porta A, et al. Power spectrum analysis of heart rate variability to assess the changes in sympathovagal balance during graded orthostatic tilt. Circulation 1994;90:1826-1831.

4. Piira OP, Huikuri HV, Tulppo MP. Effects of emotional excitement on heart rate and blood pressure dynamics in patients with coronary artery disease. Auton Neurosci. 2011;160:107-114.

5. Wulsin LR, Horn PS, Perry JL, et al. Autonomic imbalance as a predictor of metabolic risks, cardiovascular disease, diabetes, and mortality. J Clin Endocrinol Metab. 2015;100:2014-4123.

6. Buchheit M, Chivot A, Parouty J, et al. Monitoring endurance running performance using cardiac parasympathetic function. Eur J Appl Physiol. 2010;108:1153-1167. 
7. Flatt AA, Esco MR. Smartphone-Derived Heart-Rate Variability and Training Load in a Women's Soccer Team. Int J Sports Physiol Perform. 2015;10:994-1000.

8. Mazon J, Gastaldi A, Di Sacco T, et al. Effects of training periodization on cardiac autonomic modulation and endogenous stress markers in volleyball players. Scand J Med Sci Sports. 2013;23:114-120.

9. Oliveira R, Leicht A, Bishop D, et al. Seasonal changes in physical performance and heart rate variability in high level futsal players. Int J Sports Med. 2013;34:424-430.

10. Flatt AA, Esco MR. Smartphone-Derived Heart-Rate Variability and Training Load in a Women's Soccer Team. Int J Sports Physiol Perform. 2015;10:994-1000.

11. Saboul D, Balducci P, Millet G, et al. A pilot study on quantification of training load: The use of HRV in training practice. Eur J Sport Sci. 2016;16:172-81.

12. Blásquez JCC, Font GR, Ortís LC. Heart-rate variability and precompetitive anxiety in swimmers. Psicothema. 2009;21:531-536.

13. Morales J, Garcia V, García-Massó X, et al. The use of heart rate variability in assessing precompetitive stress in high-standard judo athletes. Int J Sports Med. 2013;34:144-151.

14. Flatt AA, Esco MR, Nakamura FY. Individual heart rate variability responses to preseason training in high level female soccer players. J Strength Cond Res. 2016;31:531-538.

15. Vesterinen V, Nummela A, Heikura I, et al. Individual Endurance Training Prescription with Heart Rate Variability. Med Sci Sports Exerc. 2016;48:1347-54.

16. Atkinson G, Nevill A. Statistical Methods for Assssing Measurement Error (Reliability) in Variables Relevant to Sports Medicine. Sports Med. 1998;26:217-238.

17. Hopkins WG. Measures of reliability in sports medicine and science. Sports Med. 2000;30:1-15.

18. Nunan D, Sandercock GR, Brodie DA. A quantitative systematic review of normal values for short-term heart rate variability in healthy adults. Pacing Clin Electrophysiol. 2010;33:1407-1417.

19. Task Force. Heart rate variability: standards of measurement, physiological interpretation and clinical use. Task Force of the European Society of Cardiology and the North American Society of Pacing and Electrophysiology. Circulation 1996;93:1043-1065.

20. De Freitas VH, Pereira LA, Souza EA, Leicht AS et al. Sensitivity of the Yo-Yo intermittent recovery and cardiac autonomic responses to training in futsal players. Int J Sports Physiol Perform. 2015;10:553-558.

21. Soares-Caldeira LF, de Souza EA, de Freitas VH et al. Effects of additional repeated sprint training during preseason on performance, heart rate variability, and stress symptoms in futsal players: a randomized controlled trial. J Strength Cond Res. 2014;28:2815-2826.

22. Peçanha T, Prodel E, Bartels R, et al. 24-h cardiac autonomic profile after exercise in sedentary subjects. Int J Sports Med. 2014;35:245-252.

23. Lopes FL, Pereira FM, Reboredo MM, et al. Reduction of heart rate variability in middle-aged individuals and the effect of strength training. Braz J Phys Ther. 2007;11:113-119.

24. Farah BQ, Lima AHRDA, Cavalcante BR, et al. Intra-individuals and inter-and intra-observer reliability of short-term heart rate variability in adolescents. Clin Physiol Funct Imaging. 2016;36: 33-39.

25. Sandercock G, Gladwell V, Dawson S, et al. Association between RR interval and high-frequency heart rate variability acquired during short-term, resting recordings with free and paced breathing. Physiol Meas. 2008; 29:795-802.

26. Al Haddad H, Laursen P, Chollet D, et al. Reliability of resting and postexercise heart rate measures. Int J Sports Med. 2011;32:598-605.

27. Sookan T, Mckune AJ. Heart rate variability in physically active individuals: reliability and gender characteristics. Cardiovasc J Afr. 2012;23:67-72.

28. Borg G, Ljunggren G, Ceci R. The increase of perceived exertion, aches and pain in legs, heart rate and blood lactate during exercise on bicycle ergometer. Eur J Appl Physiol Occup Physiol. 1985;54:343-349.

29. Armstrong RG, Kenny GP, Green G, et al. Diurnal variation in heart rate variability before and after maximal exercise testing. Chronobiol Int. 2011;28:344-351.

30. Hopkins W, Marshall S, Batterham A, et al. Progressive statistics for studies in sports medicine and exercise science. Med Sci Sports Exerc.2009;41:3-13.

31. Leicht AS, Allen GD. Moderate-term reproducibility of heart rate variability during rest and light to moderate exercise in children. Braz J Med Biol Res. 2008;41:627-633. 
32. Cipryan L, Litschmannova M. Intra-day and inter-day reliability of heart rate variability measurement. J Sports Sci. 2013;31:150-158.

33. Penttilä J, Helminen A, Jartti T, et al. Time domain, geometrical and frequency domain analysis of cardiac vagal outflow: effects of various respiratory patterns. Clin Physiol. 2001;21(3):365-376.

34. Ellis RJ, Sollers Iii JJ, Edelstein EA, et al. Data transforms for spectral analyses of heart rate variability. Biomed Sci Instrum. 2008;44:392-397.

35. De Vet HC, Terwee CB, Knol DL, et al. When to use agreement versus reliability measures. J Clin Epidemiol. 2006;59:1033-1039.

36. Pitzalis MV, Mastropasqua F, Massari F, et al. Short- and long-term reproducibility of time and frequency domain heart rate variability measurements in normal subjects. Cardiovasc Res. 1996;32:226-33.

37. Nakamura FY, Pereira LA, Esco MR, et al. Intra-and inter-day reliability of ultra-short-term heart rate variability in rugby union players. J Strength Cond Res. 2017;31:548-551.

38. Hopkins WG, Hawley JA, Burke LM. Design and analysis of research on sport performance enhancement. Med Sci Sports Exerc. 1999;31:472-85.

39. Maud PJ, Foster C. Physiological assessment of human fitness: Human Kinetics, 2006.

\begin{tabular}{r|r} 
ADDRESS & \\
Ana Carolina Paludo & \\
School of Physical Education and Sport & Submitted: 11/12/2017 \\
Department of Sport & Revised: 04/ 11/2018 \\
Av. Prof. Mello de Morais, 65 - Cidade Universitária & Accepted: 06/ 13/2018 \\
05508-030 - São Paulo - SP - Brazil & \\
Email: lanacpaludo@gmail.com &
\end{tabular}

